\title{
Effect of Coal Mining on Springs in the Yushenfu Mining Area of China
}

\author{
Li-min Fan, ${ }^{1,2}$ Tao Li $\mathbb{D}^{1,3}$ Maoxi Xiang, ${ }^{1,2}$ Weizhong He, ${ }^{1,2}$ Boyun Wu, ${ }^{1,2}$ Jie Peng, ${ }^{1,2}$ \\ Yonghong Li, ${ }^{1,2}$ Cheng Li, ${ }^{1,2}$ Miao-miao Zheng, ${ }^{1,2}$ Jianping Chen, ${ }^{1,2}$ Shuai Gao,, \\ Jiangli Du, ${ }^{1,2}$ and Yiwei $\mathrm{Ji}^{1,2}$ \\ ${ }^{1}$ Key Laboratory of Mine Geological Hazards Mechanism and Control, Xi'an Shaanxi 710054, China \\ ${ }^{2}$ Shaanxi Institute of Geo-Environment Monitoring, Xi'an, Shaanxi 710054, China \\ ${ }^{3}$ School of Mining \& Civil Engineering, Liupanshui Normal University, Liupanshui, Guizhou 553004, China \\ Correspondence should be addressed to Tao Li; qazwdx521@163.com
}

Received 3 July 2018; Accepted 1 September 2018; Published 28 October 2018

Guest Editor: Fangtian Wang

Copyright (C) 2018 Li-min Fan et al. This is an open access article distributed under the Creative Commons Attribution License, which permits unrestricted use, distribution, and reproduction in any medium, provided the original work is properly cited.

\begin{abstract}
The main purpose of this study was to analyze the effect of coal mining on the springs in the Yushenfu mining area of China. The results of two springs and hydrological surveys conducted in 1994 and 2015 were compared to study the occurrence and evolution of springs before and after large-scale mining. The mechanism of spring evolution and ecological effects of domain evolution were analyzed by combined groundwater monitoring and evaluation of coal mining intensity. The results show that the maximum amount of single water inflow of spring with sand infiltration recharge was more than $10 \mathrm{~L} / \mathrm{s}$, the total amount of single water inflow of spring with mixed infiltration recharge was the highest, and the ecological effect of spring with loess infiltration recharge was the most significant. In the study area, 2580 springs (group) were distributed with a total flow of $4998.9428 \mathrm{~L} / \mathrm{s}$ before 1994 and 376 residual springs (group) were present with a total flow of $996.392 \mathrm{~L} / \mathrm{s}$ in 2015. Large-scale mining decreased the regional groundwater level, thus decreasing the amount of spring water. The high intensity of mining decreased the number of springs (group) and area of water and wetland in the study area. This directly affected the watershed ecology; the ecological degradation was significant.
\end{abstract}

\section{Introduction}

Water is very important for human life, production, and ecological environment. Springs are the origin of water resources. The occurrence and evolution of springs determine the state of groundwater and surface water. Therefore, it is important to study the characteristics of spring water.

Coal mining of China is moving to the west; Western China has become the main coal-producing area, accounting for $70 \%$ of the China's coal output. However, Western China generally lacks water resources and has a fragile ecological environment [1]. By studying the effect of coal mining on the environment, the scientific community has already made a conclusion: coal mining directly affects the ecological environment $[2,3]$ and small-scale mining activities also cause severe damage to the ecosystem [4]. Therefore, in the early stage of coal mining in Western China, some experts realized the importance of water resources and environment in the ecologically fragile mining area $[5,6]$, proposed the concept of "water-preserved mining" [7,8], and carried out a series of research [9-19].

The distribution characteristics and forming conditions of spring in the southern edge of Mu Us Desert were analyzed by $\mathrm{Wu}$ and other researchers. Ma and other scholars classified the influence degree of coal mining on springs and discussed the influence mechanism of coal mining on springs. In addition, the effect of coal mining on water resources and ecological environment has been extensively investigated $[2,3,20]$. 
This study analyzed the mechanism of spring evolution in the Yushenfu mining area by comparing the evolution of springs in the Yushenfu mining area in northwest China around 21 years ago and combining the study of collapse caused by coal mining.

\section{Materials}

2.1. General Situation of the Study Area. The study area, Yushenfu mining area, is located in Shaanxi Province of China. The study area is $\sim 7800 \mathrm{~km}^{2}$, north latitude of $38^{\circ} 10^{\prime}$ $-39^{\circ} 30^{\prime}$ and east longitude of $109^{\circ} 0^{\prime}-110^{\circ} 60^{\prime}$ (Figure 1). The altitude of the study area is $\sim 1200 \mathrm{~m}$, the highest point is $1448.7 \mathrm{~m}$, and the lowest point is $932 \mathrm{~m}$. Three types of geomorphology are present, namely, aeolian landform, sandcovered loess ridge and hilly, and loess ridge and hilly. According to the meteorological observation in Yuyang District, the annual average precipitation is $420.4 \mathrm{~mm}$ with the maximum annual rainfall of $565.3 \mathrm{~mm}$ and the minimum annual rainfall of $270.8 \mathrm{~mm}$. Precipitation mainly occurred in July to September, accounting for $62.9 \%$ of the annual precipitation.

The Yushenfu mining area is in the Ordos Basin of North China. The geological tectonic is simple. The strata are from the old to the new: Upper Triassic Yongpoing formation $\left(\mathrm{T}_{3} y\right)$, Yan'an formation $\left(\mathrm{J}_{2} y\right)$, Zhiluo formation $\left(\mathrm{J}_{2} z\right)$, Anding formation $\left(\mathrm{J}_{2} a\right)$ of Middle Jurassic, Lower Cretaceous Luohe formation $\left(\mathrm{K}_{1} l\right)$, Neogene Pliocene series Debao formation $\left(\mathrm{N}_{2} b\right)$, Quaternary Middle Pleistocene series Lishi formation $\left(\mathrm{Q}_{2} l\right)$, Quaternary Upper Pleistocene Salawusu formation $\left(\mathrm{Q}_{3} \mathrm{~s}\right)$, aeolian deposit $\left(\mathrm{Q}_{4} e o l\right)$, and alluvial deposit $\left(\mathrm{Q}_{4} a l\right)$ of Quaternary Holocene series. The main coal bearing strata are Middle Jurassic Yan'an formation. The main minable seam has 4 layers, of which $2^{-2}$ and $4^{-3}$ of the whole area can be mined and $3^{-1}$ and $5^{-3}$ of the upper part can be mined.

The groundwater in this area is mainly supplied by atmospheric water. The direction of shallow seepage flow is basically consistent with topographic relief. The deep seepage flow is basically runoff from northwest to southeast. The buried depth of groundwater in the western desert beach area is generally $0 \sim 3 \mathrm{~m}$, and it has gradually increased in the eastern part. The buried depth of groundwater in the loess ridge and hilly area is generally greater than $15 \mathrm{~m}$. Groundwater is mainly in valleys with spring in the form of emission. Groundwater is mainly discharged in the form of springs in gullies.

\subsection{Spring Characteristics before Large-Scale Mining}

2.2.1. Hydrological Background of Spring Formation. The stratigraphic structure of the study area successively from the new to the old is $\mathrm{Q}_{4}$ eol (Mu Us formation), Q3 (Salawusu formation), Miocene series (Lishi formation, the Loess), Pliocene series (Red clay), Jurassic Zhiluo formation, and Yan'an formation. Currently, Yan'an formation containing coal is the main mining layer. The formation of a spring can be divided into three parts (Figure 2): (i) spring group produced by aeolian landform infiltration, (ii) spring group produced by the infiltration of sand-covered loess ridge and hilly, and (iii) spring group produced by the infiltration of loess ridge and hilly. Notably, the three parts do not include the distribution area, bedrock valley geomorphology with limited infiltration, and geomorphology of the burnt zone. Because the water holding capacity of these strata is limited, the gush of dry season spring mainly comes from the above three parts with a high ecological significance.

(1) Spring Produced by Aeolian Landform Infiltration. The Salawusu formation is the main aquifer in the study area. No water barrier is present between the Salawusu and $\mathrm{Mu}$ Us formations, constituting a unified loose sand aquifer. It is generally called the aquifer of Salawusu formation. The aquifer of Salawusu formation receives the atmospheric precipitation, condensation recharge, rapid infiltration, runoff in the sand layer, enrichment in the low-lying area on the top of Jurassic, and formation of a rich water area. After the erosion of local surface runoff to the aquifer, the descending spring is excreted and forms the spring group (Figure 2). Because the topography of sandy land is small, the number of springs in this area is limited, but the total volume is the largest.

(2) Spring Produced by Infiltration of Sand-Covered Loess Ridge and Hilly. The area of sand-covered loess ridge and hilly belongs to the transition area of $\mathrm{Mu}$ Us Desert and Loess Plateau (Figure 2), and the thickness of sand layer is relatively limited. Because of the relatively low terrain compared with the aeolian landform area, the lateral recharge of groundwater is better owing to aeolian landform infiltration and fluctuation of loess terrain, most of the groundwater is exposed, and it is easy to contact with the spring spot. The output of spring is the largest in this area, but this part of the spring is more sensitive. The instability of underlying aquifer causes its attenuation; at the same time, the decline of groundwater level in the regional loose layer also easily makes it disappear.

(3) Spring Produced by Infiltration of Loess Ridge and Hilly. The loess layer acts as a weak permeable layer. This layer has a certain infiltration capacity for precipitation, but it is very limited compared with the amount of sand infiltration. The loess has better water-holding property; long-term infiltration of water resources occurs in the stratum. After cutting the loess topography, concentrated discharge of groundwater occurs in the medium such as the top surface of bedrock or burned rock, forming the main drainage spring spots of this type of geomorphology.

2.2.2. Distribution of the Spring Group. The spring of Mu Us Desert is mainly distributed in the east edge of Kuye River, Tuwei River, and the upper reaches of Yuxi River, a tributary of Wuding River. The spring is distributed on the north-east zonal distribution of the plane (Figure 3). The springs converge to form Kuye River, Tuwei River, and Yuxi River. Yuxi River is a tributary of Wuding River. Kuye River, Tuwei River, and Wuding River are the tributaries of Yellow River. They are the main supply rivers in the middle reaches of Yellow River. 


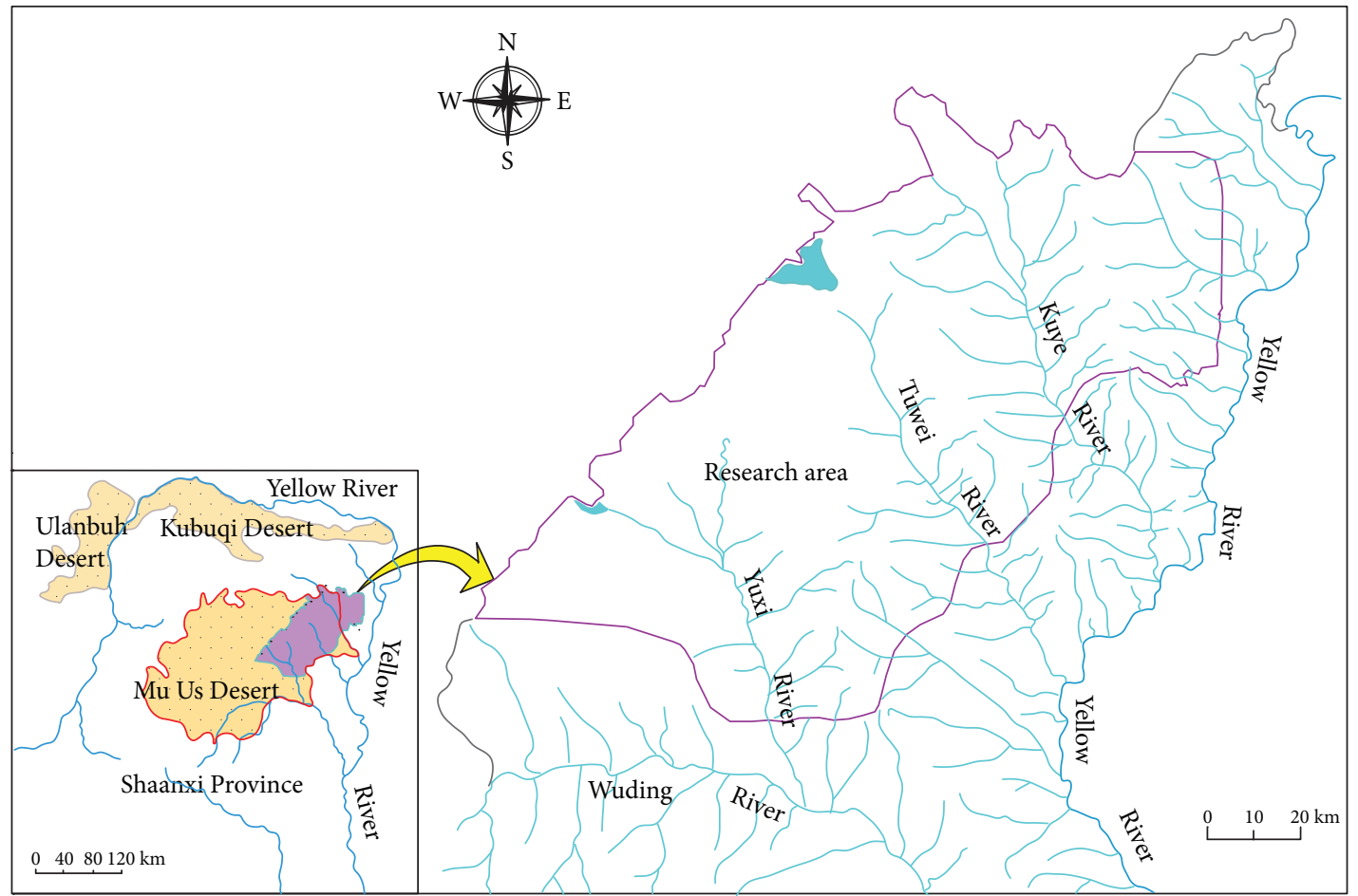

FIGURE 1: Boundary of the research area.

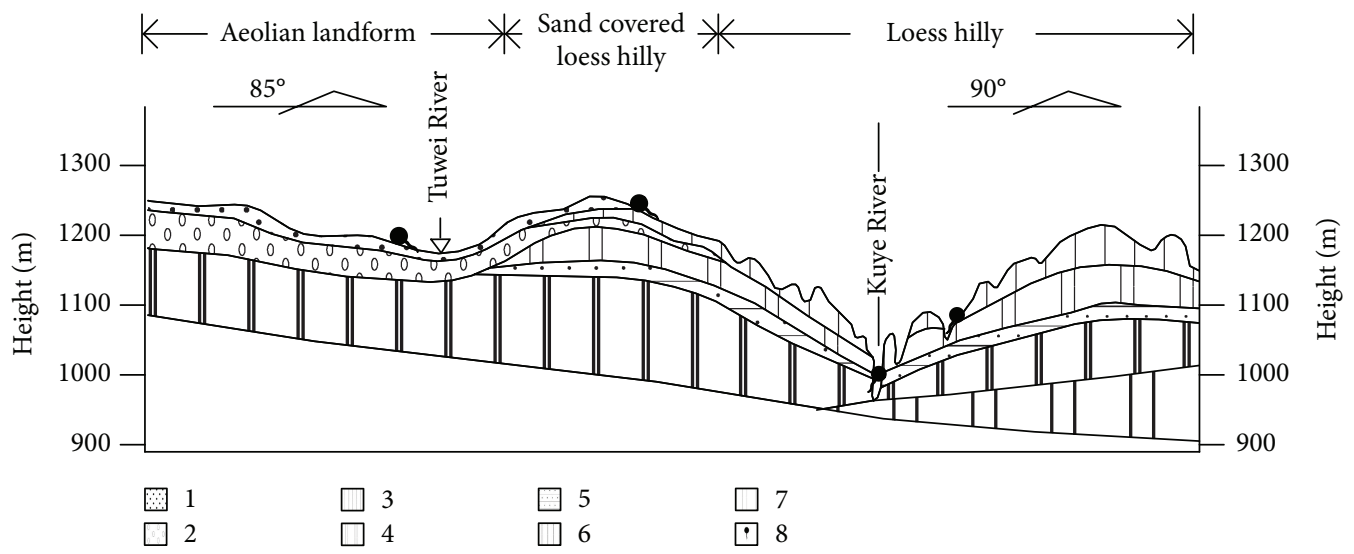

Figure 2: Classical hydrogeological profile. 1: Aeolian sand; 2: fluvial sand; 3: Upper Pleistocene series loess; 4: Middle Pleistocene series loess; 5: sandstone; 6: mudstone; 7: siltstone; 8: spring.

All the water originates from the spring of Salawusu formation, including the tributary of Yuxi River, Sa River, Qin River, Geqiu River, and Heze River of Yidao, Erdao, Sandao, Sidao, and Wudao, the upper reaches of Hongliugou in Tuwei River, the Lucaogou of Kuye River, Houjiamu River, and Ulambra Valley. Large springs are produced on the coast of Tuwei River, such as Qingshui Spring, Caitugou Spring, and Heilonggou Spring.

Figure 3 shows that a concentrated distribution of spring was formed in the basin of Kuye River and Tuwei River. This area was the distribution band of the spring group distributed in the NE direction and concentrated on the mouth of spring.

Many types of methods are available for the classification of spring spots in the study area. The most direct method is to classify the gush strata of spring; it can be divided into outcropping spring of Salawusu formation $\left(\mathrm{Q}_{3} s\right)$, outcropping spring of loess and hipparion laterite, outcropping spring of burnt rocks $\left(\mathrm{J}_{2} y\right)$, outcropping spring of Jurassic $\left(\mathrm{J}_{2} z\right.$ or $\left.\mathrm{J}_{2} y\right)$, and outcropping spring of other layers. This type of classification is more intuitive, but its distribution rule is more discrete and has no rules. By comparison, combined with 


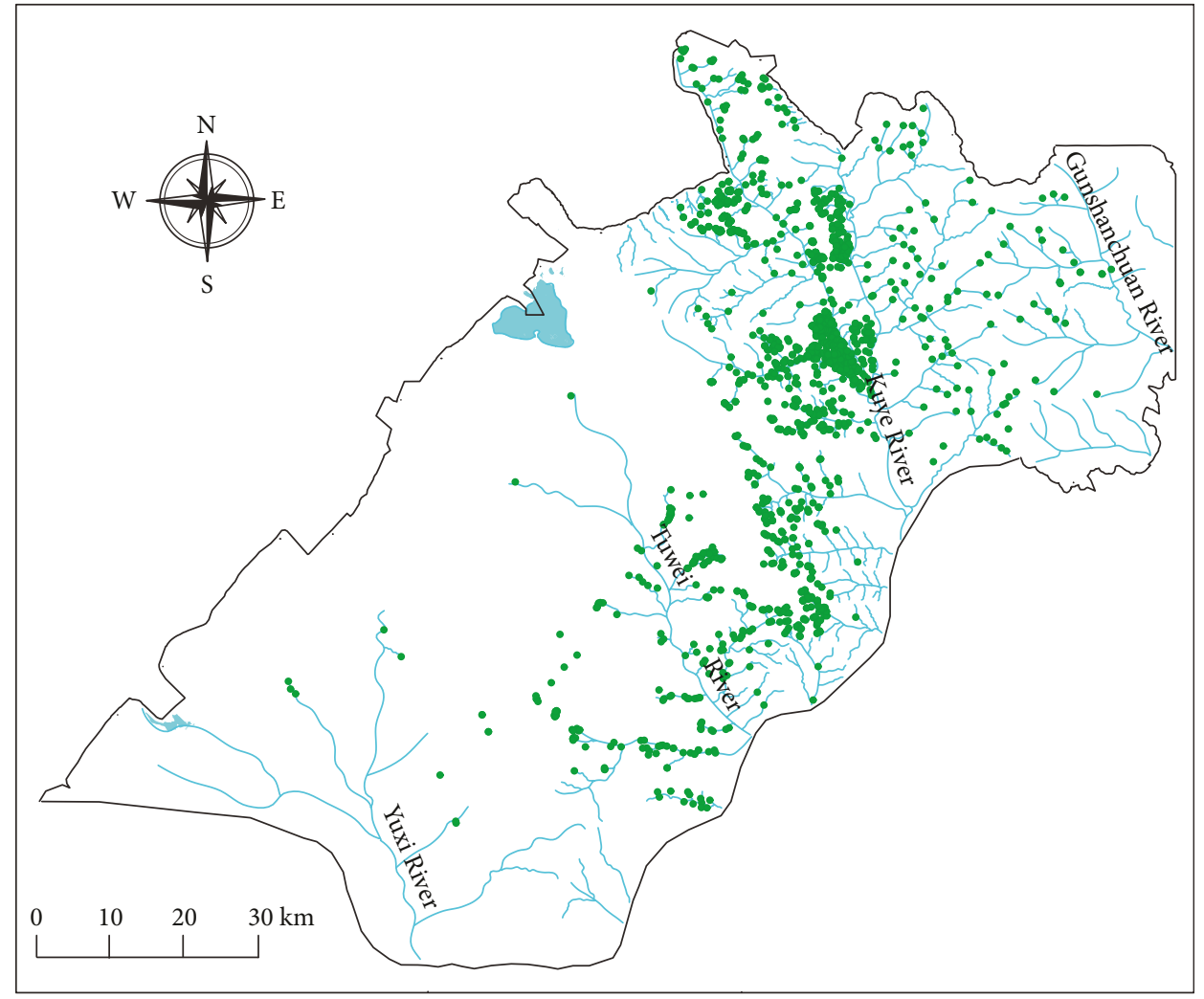

- Springs

FiguRE 3: Distribution of spring groups in the study area before large-scale mining.

Figure 4, the spring spots in the study area can be divided into three types, namely, recharge spring spot of sand infiltration, recharge spring spot of loess infiltration, and recharge spring spot of mixed infiltration (Figure 4). Importantly, the three types of geomorphologic infiltration landforms are different, but it can be centrally excreted in each layer. Other landforms were not considered. On one hand, the fissure medium of bedrock and fire rock formation suffers from a huge loss of infiltration water in the rainy season; the ecological significance is not large. On the other hand, its distribution area and infiltration coefficient are very limited, leading to the classification.

(1) Recharge Spring Spot of Sand Infiltration. Atmospheric precipitation falls on the relatively flat sandy land, significantly replenishing the sandy groundwater. Because of the fluctuation of underlying loess stratum, it converges to the lower ground. A small amount of water is further infiltrated into other strata after the infiltration, making each aquifer in this area with relatively strong water abundance. Each aquifer produces a drainage in the form of descending springs in the valley cutting area, such as Yuxi River and its tributaries. Because of the slow seepage of groundwater in the sandy land, it acts as the spatiotemporal regulation. This makes these spring spots continue to flow at all seasons without interruption, thus playing an important role in supporting the ecology of this region. The representative of this type of spring is like each branch of the stream group in the upper reaches of Yuxi River, such as phase 3 of the Yushen mining area.

(2) Recharge Spring Spot of Loess Infiltration. Atmospheric precipitation falls in the undulating Loess Plateau. Because precipitation in the study area is dominated by rainstorm, the loess produces mud crust that hinders infiltration. The infiltration coefficient is only about a quarter of sandy land or even lower. The flood torrent gathered from a large amount of runoff in the rainy season further cuts the topography of the area. Limited infiltration into the loess formed a certain amount of water resources after a long period of accumulation, rich in flat terrain and thicker soil layer, and a small amount of further infiltration occurs in the underlying aquifers. This groundwater gushes out at the terrain cutting area, forming a small number of spring spots. However, because loess has stronger capillarity than sandy soil, it is more suitable for vegetation development, forming one of the best ecosystems in the study area. Because of limited supply sources, as far as a single spring is concerned, it is relatively fragile. Because the permeability coefficient of loess is smaller than that of sandy land, the radius of influence is smaller after it is affected. This indicates that the ability of these springs to resist regional hydrological changes is stronger than that of sandy land. The typical representative of this type 


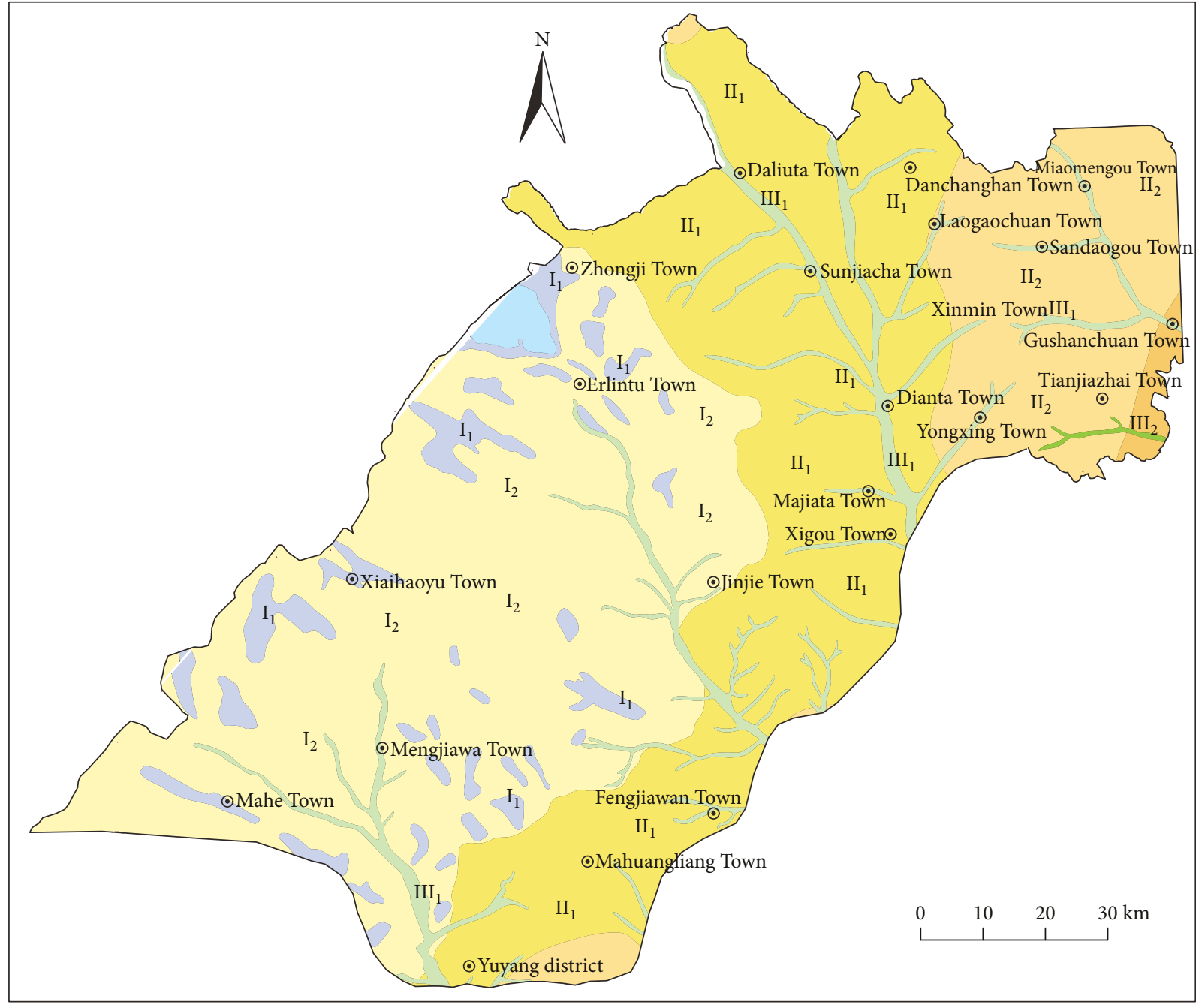

\section{Aeolian-sand area \\ $\mathrm{I}_{1}$ Bottomland area \\ $\mathrm{I}_{2}$ Desert area}

\author{
2. Loess geomorphy area \\ $\mathrm{II}_{1}$ Sand covered loess ridge area \\ $\mathrm{II}_{2}$ Loess ridge and hilly area \\ $\mathrm{II}_{3}$ Loess hilly area
}

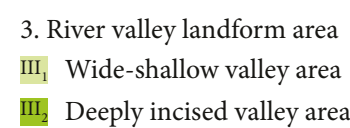

$\mathrm{III}_{2}$ Deeply incised valley area

FIGURE 4: Geomorphologic map of the study area.

of spring is the spring group in the Miaogoumen of the Shenfu mining area.

(3) Recharge Spring Spot of Mixed Infiltration. A transitional area is present between the abovementioned two types of topographies and landforms. A part of the loess in the area is exposed. A part of the sand is exposed, but the thickness is thinner, even intersecting the exposed sand. Both the infiltration and runoff are complex and diverse. It is not possible to accurately describe the initial source of supply for some springs. Because of the interlacing of strata, the groundwater runoff (mainly sand runoff) from the sandy land and yellow land is exposed in large quantities here. They form the largest number of springs (groups) in the study area. Because of the complexity of such springs, they are also complex and diverse under the influence of human activities. The typical representative of this type of spring is the spring group in the Zhangjiamao coal mine of the Shenbei mining area.

2.2.3. Ecological Significance of Spring. In the study area, the water resources are poor and the ecological environment is fragile. This is because the water resources are collected near the natural outcropping springs in the low-lying terrain and valley zone. Generally, it has a relatively good ecological environment and is suitable for survival. It often becomes the human living agglomeration and multiple natural villages. Humans formed a unique desert culture with a long-term integration of this natural environment. At the same time, the spring water was collected over the years, dissecting topography and eventually converging into a river to become a tributary of Yellow River and supplying the Yellow River. 


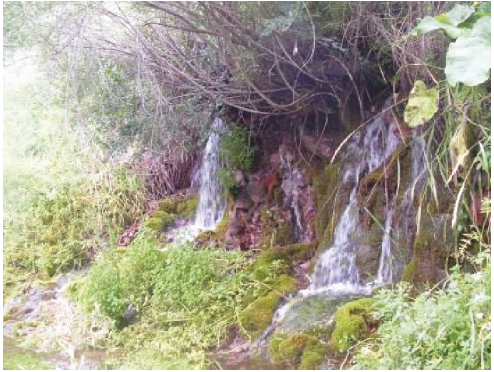

(a)

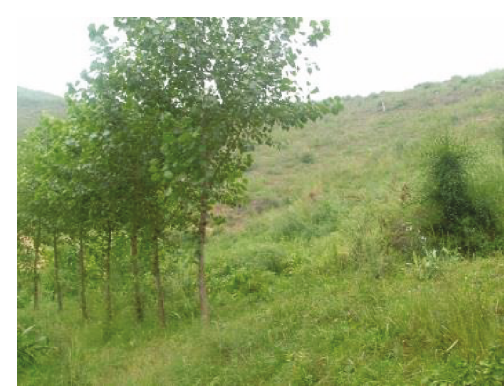

(b)

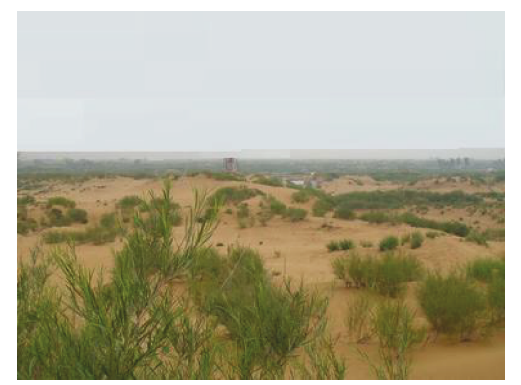

(c)

FIGURE 5: Ecological environment of small watershed in the spring area. (a) The mouth of Caitugou spring, (b) the vegetation of north side of downstream channel in Caitugou spring, (c) desert vegetation in no spring area.

In the study area, the natural ecological environment is completely different with or without springs (Figure 5). In the area without springs, floating sand dunes are exposed, vegetation coverage is low, and ecological environment is fragile. In the area with springs, water and grass are developed, vegetation coverage is clearly improved, and the vegetation on both sides of valley is well developed. It is suitable for human living and planting potatoes, corn, rice, leguminous crops, etc.

\subsection{Present Large-Scale Mining Situation in the Study Area.} Since the 1980s, the geological study of Jurassic coal field in Northern Shaanxi of China has never stopped and dozens of geological study reports have been submitted. Three coal mining areas have gradually formed: mining area of northern Shenmu, mining area of Xinmin, and mining area of Yushen. It is also within the scope of this study. The Jurassic coal field in Northern Shaanxi belongs to the coal stratum area, and the coal-bearing area is $\sim 27,140 \mathrm{~km}^{2}$ in the entire area. The structure is simple; the coal seam is stable in the region with total resources of $\sim 2400 \times 10^{8} \mathrm{t}$ in the entire area, and the proven resources are $\sim 1400 \times 10^{8} \mathrm{t}$.

Through field studies and data collection, 190 coal mines were investigated, including 23 mines in Yuyang District, 101 mines in Shenmu City, and 66 mines in Fugu County. The total mining area is $2881.21121 \mathrm{~km}^{2}$, including $423.473 \mathrm{~km}^{2}$ in Yuyang District, $1735.9689 \mathrm{~km}^{2}$ in Shenmu City, and $721.769314 \mathrm{~km}^{2}$ in Fugu County.

The statistical results indicate 49 small mines with designed mining capacity of less than $0.45 \mathrm{Mt} / \mathrm{a}, 52$ large mines with mining capacity of more than $1.2 \mathrm{Mt} / \mathrm{a}$, and 89 medium mines. The design and production capacity of large
TABle 1: Statistic of the coal scale.

\begin{tabular}{lccc}
\hline District & Yuyang District & Shenmu City & Fugu County \\
\hline Area $\left(\mathrm{km}^{2}\right)$ & 423.473 & 1735.9689 & 721.769314 \\
Scale & & & \\
$\quad$ Large-scale & 8 & 31 & 13 \\
Mid-scale & 7 & 43 & 38 \\
Small-scale & 8 & 25 & 15 \\
\hline
\end{tabular}

mines are more than $10 \mathrm{Mt} / \mathrm{a}$, including Yujialiang coal mine of China Shenhua, Shigetai coal mine, Halagou coal mine, Daliuta coal mine, Huojitu coal mine, Hongliulin coal mine of Shaanxi coal and chemical industry group, and Ningtiaota coal mine. At present, the study area is basically well drilling and the comprehensive mechanized mining method is used (Table 1).

\section{Methods}

3.1. Spring Change with Coal Mining. According to the coordinates of observed spring spots in 1994 (Figure 3), the corresponding spring spots were studied after 21 years. The month of the second investigation was the same; both surveys were conducted during the rainy season.

The study was completed through field visits, analysis, taking photographs, recording videos, and filling in hydrological questionnaire and field record. The content of the study includes the mining area of spring, topography, water outcropping formation, aquifer description, depth to the water table of the well, spring flow, historical changes in the 


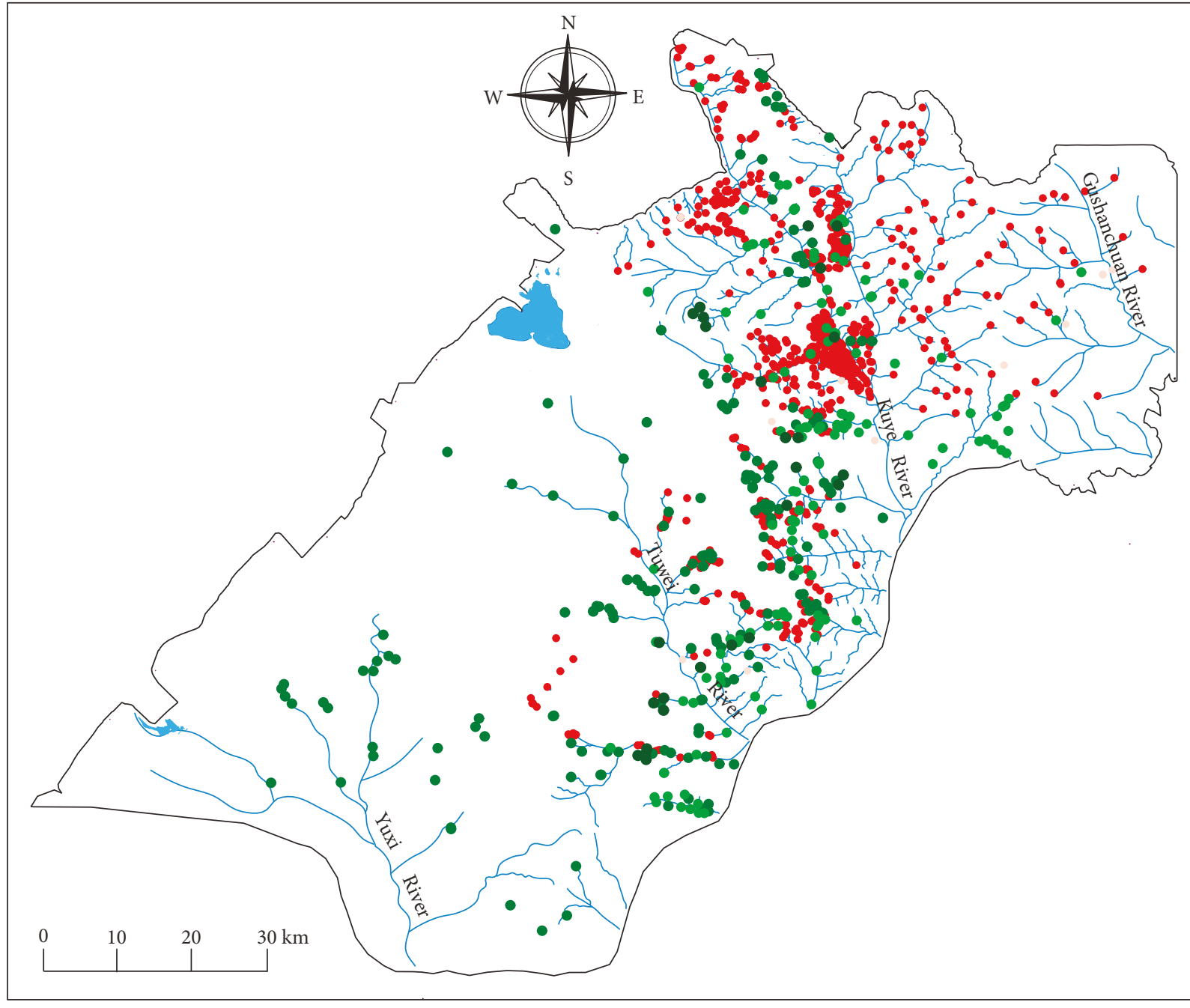

- Dried springs

- Springs outcropping from sandstone aquifer

Springs outcropping from loess aquifer

- Springs outcropping from Salawusu group aquifer

- Springs outcropping from burnt rock aquifer

FIgURE 6: Distribution of springs in 2015.

water level and flow, use of the well and spring, water temperature, and air temperature. GPS was used to locate the coordinates of wellhead or spring outcrop. A scale or an ammeter was used to measure the depth of the water table, and a triangular weir was used to measure the flow of spring water. The results are shown in Figure 6.

3.2. Groundwater Dynamics of Coal Mining. A total of 10 long-term monitoring wells were arranged in this study. Their position distribution is shown in Figure 7, and the basic information is shown in Table 2. The sand aquifer has four wells. The sandstone aquifer has five wells, and the loess aquifer has one well.

3.3. Evaluation of Intensive Mining. The intensity of coal mining was comprehensively evaluated from area and space mining intensity. The area mining intensity refers to the proportion of coal resources exploited and the total amount within the scope of the unit area (Table 3). The spatial mining intensity is mainly evaluated using two indicators: the mining height and specification of coal face. A large-scale coal face with a height of $>4.5 \mathrm{~m}$, length of $>200 \mathrm{~m}$, and excavating length of $>2000 \mathrm{~m}$ is known as an intensive mining area. The area with a mining height of $1.3-4.5 \mathrm{~m}$, coal face length of $100-200 \mathrm{~m}$, and excavating length of $1000-2000 \mathrm{~m}$ is defined as a medium-intensive mining area. The area with a mining height of $<1.3 \mathrm{~m}$ irrespective of the length of coal face and excavating length has a relatively low influence with the development degree of geological hazard on the surface, known as a low-intensity mining area.

Table 3 shows that the coal mining intensity is determined by the area of mining proportion and mining height, but in practical production and strength division, other factors should not be ignored, such as the ground subsidence, surface crack, and buried depth of the groundwater level. 


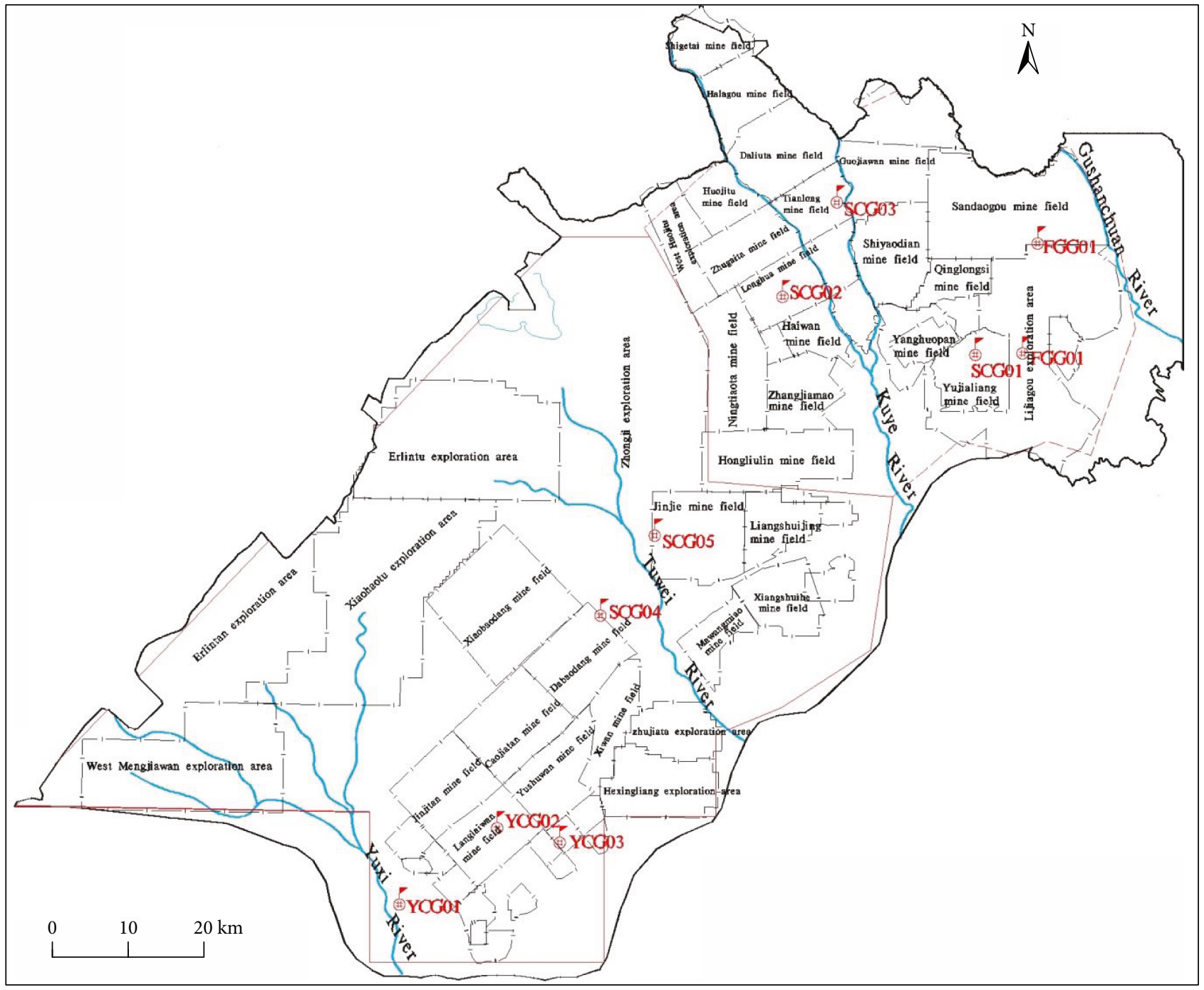

SCG05 Number and location of long-term monitoring well

Figure 7: Distribution of long-term monitoring wells.

The mining intensity of the study area can be divided into an extremely intensive mining area, an intensive mining area, a medium-intensive mining area, and a low-intensive mining area according to the mining height, surface mining proportion, ground subsidence, surface crack, and hydrological characteristics (Figure 8).

3.3.1. Extremely Intensive Mining Area. Daliuta area is rich in coal resources and has a long history of mining. The mining area of Shigetai coal mine, Halagou coal mine, Daliuta coal mine, Huojitu coal mine, and Hejiata coal mine is wide. The proportion of the mining area is $>60 \%$, the mining height is $>4.5 \mathrm{~m}$, and the coal face is long. Therefore, this area belongs to an extremely intensive mining area, covering an area of $576.04 \mathrm{~km}^{2}$.

3.3.2. Intensive Mining Area. The area of an intensive mining area is $1256.48 \mathrm{~km}^{2}$; it belongs to Sunjiacha, Mjiata,
Xigou, Dianta, and Yongxing Town of Shenmu City. The terrain in this area is undulating due to river cutting. The coal mine in this area is widely distributed, mining activity is frequent, and the underground water level is significantly low.

3.3.3. Medium-Intensive Mining Area. The area of a mediumintensive mining area is $391.8 \mathrm{~km}^{2}$. Although coal mining exists in the area, the mining area is small, the mining seam is single, the mining height is small, and the decline in the water table is small. No geological hazards such as ground collapse and surface crack are present.

3.3.4. Low-Intensive Mining Area. The area of a low-intensive mining area is $514 \mathrm{~km}^{2}$. The exploitation range of Hengruiyuan and Yaoqu coal mines in Shenmu City is small. The proportion of the mining area of these mines accounts for $6.5 \%$ and $0.6 \%$, respectively, and the mining height is 
TABLE 2: Basic information statistics of the long-term monitoring well.

\begin{tabular}{|c|c|c|c|c|c|}
\hline Number & Location & Geomorphology & $\begin{array}{c}\text { Geologic } \\
\text { age }\end{array}$ & Lithology & Mine field \\
\hline SCG01 & Zhangminggou village, Dianta Town, Shenmu & Loess ridge and hilly & $\mathrm{J}_{2} y$ & Sandstone & Yujialiang mine field \\
\hline SCG02 & Wulansetai village, Daliuta Town, Shenmu & River valley landform & $\mathrm{J}_{2} y$ & Sandstone & Dahaize mine field \\
\hline SCG03 & Hezegou village, Jinjie Town, Shenmu & Aeolian sand & $\mathrm{Q}_{4} \mathrm{eol}$ & Aeolian sand & Jinjie mine field \\
\hline SCG04 & Heilonggou village, Dabaodang Town, Shenmu & River valley landform & $\mathrm{J}_{2} y$ & Sandstone & Delong coal mine \\
\hline YCG01 & Liushutan village, Jinjitan Town, Yuyang District & Aeolian sand & $\mathrm{Q}_{3} \mathrm{~s}$ & Fine sand & Changjialiang coal mine \\
\hline YCG02 & $\begin{array}{l}\text { Lierping's courtyard, Liuxiang village, Mahuangliang } \\
\text { Town, Yuyang District }\end{array}$ & Aeolian sand & $\mathrm{Q}_{3} s+m$ & $\begin{array}{l}\text { Fine sand } \\
\text { and loess }\end{array}$ & Hanglaiwan coal mine \\
\hline YCG03 & $\begin{array}{c}\text { Niujialiang village, Niujialiang Town, } \\
\text { Yuyang District }\end{array}$ & Loess hilly & $\mathrm{Q}_{3} m$ & $\begin{array}{l}\text { Malan group } \\
\text { loess }\end{array}$ & Liuxiang coal mine \\
\hline YCG04 & Chaheze farm, Hongshiqiao, Town, Yuyang District & Aeolian sand & $\mathrm{Q}_{3} s$ & Fine sand & $\begin{array}{c}\text { Mengjiawan exploration } \\
\text { area }\end{array}$ \\
\hline FCG01 & Huolaigou village, Sandaogou Town, Fugu County & River valley landform & $\mathrm{J}_{2} y$ & Sand shale & Sandaogou coal mine \\
\hline FCG02 & Dalumao village, Xinmin Town, Fugu County & River valley landform & $\mathrm{J}_{2} y$ & Sand shale & Huafu coal mine \\
\hline
\end{tabular}

TABLE 3: Index of the coal mining intensity level.

\begin{tabular}{|c|c|c|c|c|}
\hline \multirow[b]{2}{*}{ Mining height/m } & \multicolumn{4}{|c|}{ Coal mining intensity level } \\
\hline & $\begin{array}{c}\text { Productive area/mining } \\
\text { area }(\geq 60 \%)\end{array}$ & $\begin{array}{c}\text { Productive area/mining } \\
\text { area }(60 / 30 \%)\end{array}$ & $\begin{array}{c}\text { Productive area/mining } \\
\text { area }(30 / 10 \%)\end{array}$ & $\begin{array}{c}\text { Productive area/mining } \\
\text { area }(\leq 10 \%)\end{array}$ \\
\hline$\geq 4.50$ & Extremely & High & Medium & Low \\
\hline $1.30-4.50$ & High & Medium & Medium & Low \\
\hline$\leq 1.30$ & Medium & Low & Low & Low \\
\hline
\end{tabular}

$1.2 \mathrm{~m}$ and $3.0 \mathrm{~m}$, respectively. The excavating length of mining face is short. In addition, no obvious change was observed in the depth to the water table in the coal mine area; therefore, this area can be classified as a low-intensive mining area.

\section{Results and Discussion}

4.1. Quantitative Change Analysis of Springs with Mining. According to the background data and field study, 2580 springs were present in the entire area before the coal development. This study revealed 376 springs with water. The rest of springs dried up completely, and the attenuation rate is $84 \%$, as shown in Figure 9.

Regarding the amount of springs, the attenuation rate of spring quantity reached over $90 \%$. The springs were located in the coal mines of Shigetai, Daliuta, and Huojitu in the north of Shenmu City, the coal mines of Sunjiacha, Haiwan, Zhangjiagou, and Ningtiaota in the middle of Shenmu City, and the coal mines of Yanghuopan and Shiyaodian in the east of Shenmu City. Except for the spring seepage with one place for stratum excavation in Shigetai coal mine, the rest of natural springs basically disappeared. The attenuation rate of spring quantity within the mining area of Halagou, Dahaize, Liangshuijing, Ningtiaota, Jingjie, and Zhangjiamao is $70-80 \%$. The attenuation rate of spring quantity in the mine field of Yushuwan, Mawangmiao, and Zhujiata is $40-50 \%$. The spring of Dabaodang did not dry up; a certain decrease in flow rate was observed compared with that before 1994 .

According to this classification of spring spot, the attenuation rate of spring spot quantity with mixed infiltration supply is concentrated in $80-100 \%$. The attenuation rate of spring spot quantity with loess infiltration supply is the second; this is concentrated in $60-80 \%$. The attenuation rate of spring spot quantity with sandy land infiltration supply is the minimum; this is concentrated in $0-30 \%$.

4.2. Analysis of Variation in Discharge of Spring with Mining. Regarding spring flow, the total flow of the spring group in 1994 was $\sim 4292.2 \mathrm{~L} / \mathrm{s}$ and the total flow of the spring group sharply decreased to $996.392 \mathrm{~L} / \mathrm{s}$ in 2015 with an attenuation rate of $76 \%$. Compared with 1994, the attenuation rate of spring flow within the mining area of Shigetai, Huojitu, Daliuta, Hejiata, Zhugaita, Sunjiacha, Haiwan, Shiyaodian, Yanghuopan, Zhangjiamao, and Ningtiaota reached over $90 \%$. The attenuation rate of spring flow within the mining area of Qianshipan, Dahaize, Liangshuijing, Yujialiang, Xiangshuihe, Jingjie, and Zhujiata is $70-90 \%$. The attenuation rate of spring flow within the mining area of Yushuwan, Caojiatan, Mawangmiao, and Hexingliang is less than $70 \%$ (Figure 10). 


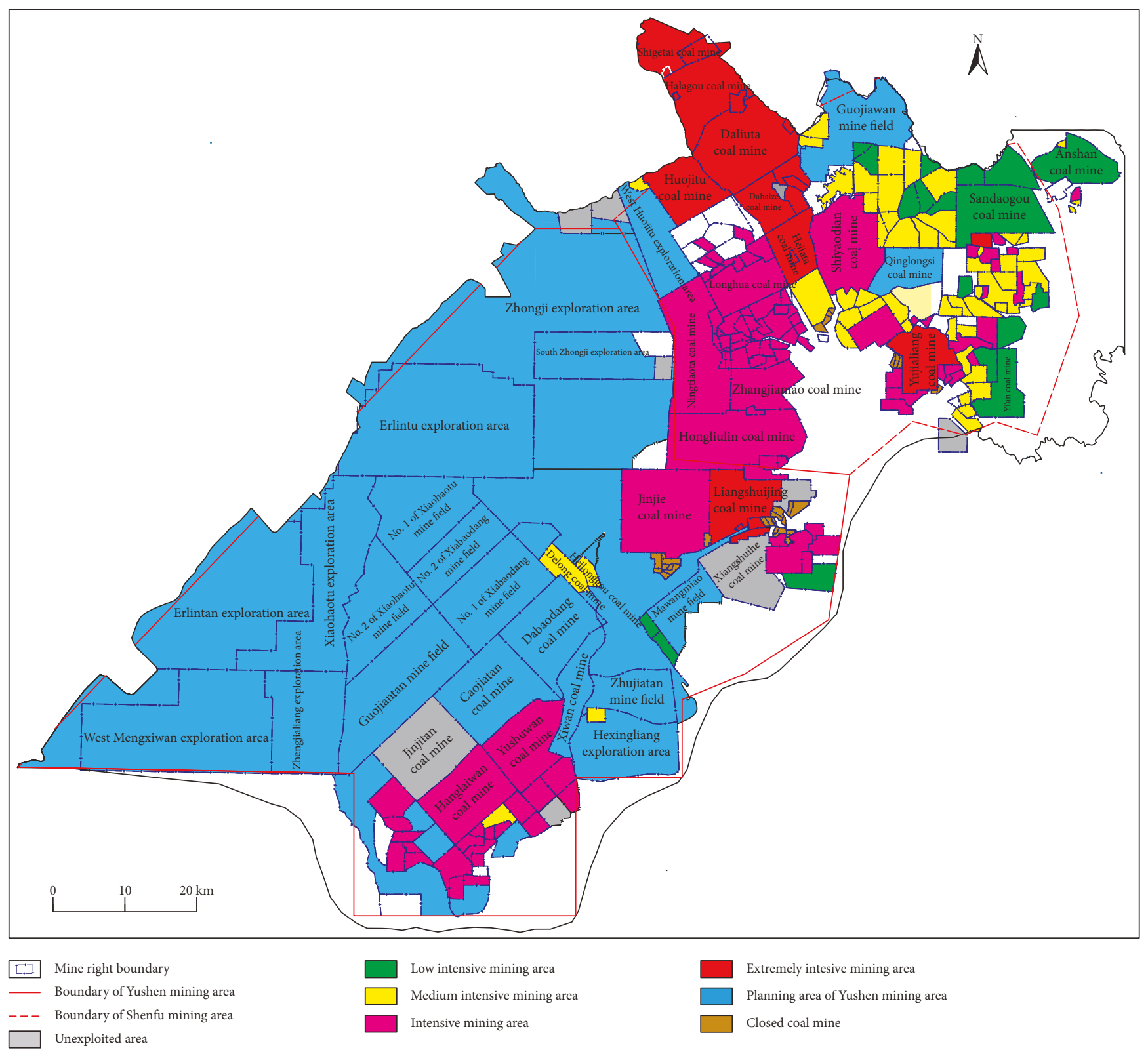

Figure 8: Zoning plan of the coal mining intensity level.

According to the spring classification of Section 2.2.1, the attenuation rate of spring flow with mixed infiltration is concentrated in $80-100 \%$. The attenuation rate of spring spot quantity with loess infiltration supply is the second, concentrating in $70-90 \%$. The attenuation rate of spring spot quantity with sandy land infiltration supply is the minimum, concentrating in $10-50 \%$. The overall trend is similar to decline, but because of landing funnel, etc., the other two types of spring spots occur by combining the flow attenuation effect of infiltration springs. The overall trend is similar to quantitative attenuation. However, because of the depression cone, the other two types of spring spots are affected by the attenuation of mixed infiltration supply with the spring spot flow.

\subsection{Changing Mechanism Analysis of Spring with Mining}

4.3.1. Decrease in Spring Quantity by the Decline of the Regional Groundwater Level. A comparison of the investigated 541 water level monitoring sites in 2015 with 1994 showed that the phreatic water level in the study area has a different degree of decline compared with the last century (Figure 11). The region with the greatest decline of the water level is located in the Shendong mining area of Shigetai, Halagou (Figure 12), Daliuta, Huojitu, Dahaize, Zhugaita, Longhua, Shiyaodian, and the detailed study area of Jingjitan-Mahuangliang in Yuyang District. These areas are intensive mining areas. Most of them form a concentrated strip of the mined-out section, and the drop of the water level 


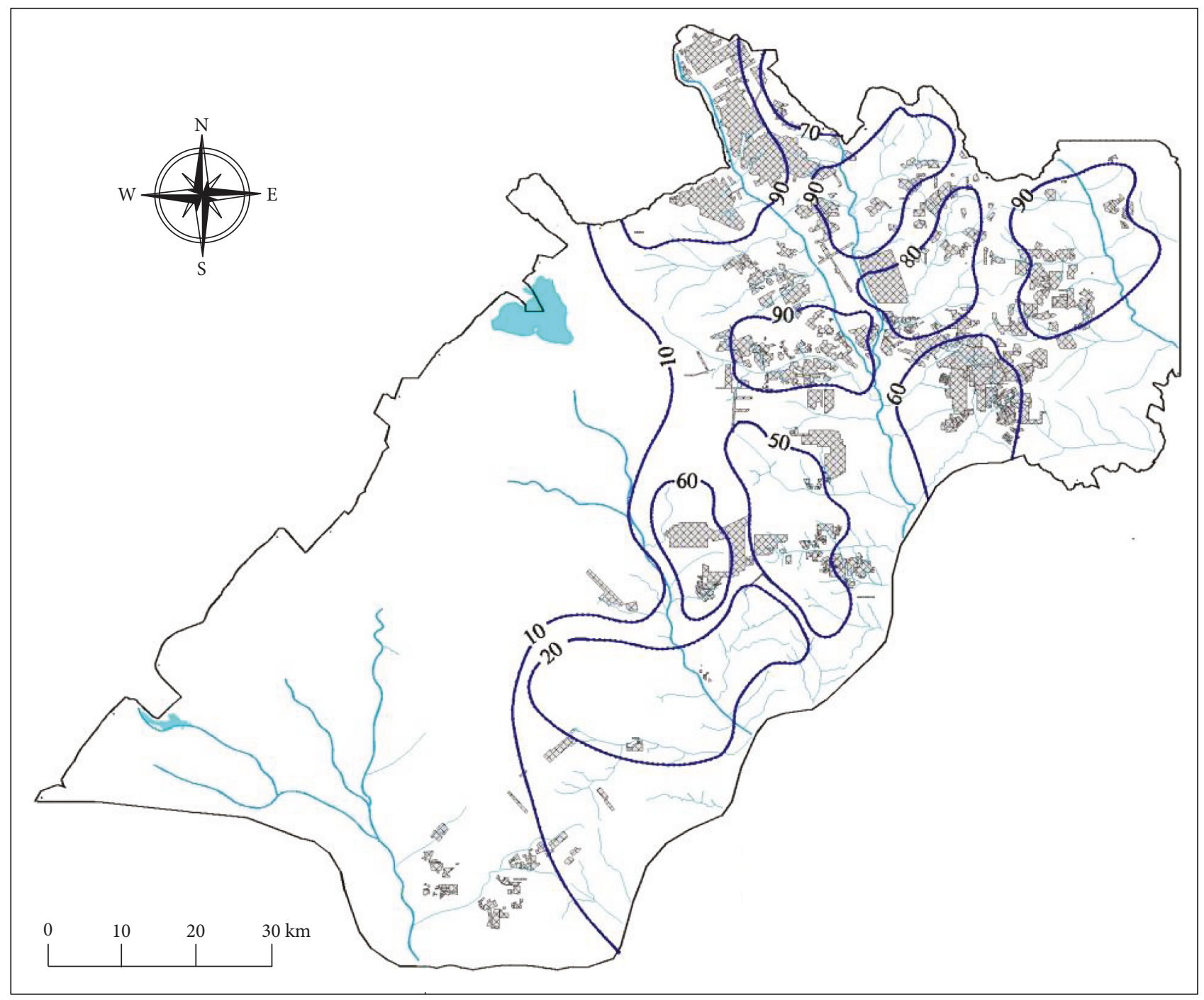

$-70-7$ Attenuation ratio of quantity (\%)

Mined-out area

FIGURE 9: Contour map of the attenuation ratio of spring (group) quantity.

is $>15 \mathrm{~m}$. Because of the sharp decrease of the water level in these areas, the water level around these mine fields also decreased to a certain extent with a water level drop of 5$15 \mathrm{~m}$. The area with the water level drop of $1-5 \mathrm{~m}$ is mainly located in the east of the Shenfu mining area and the east of the Yushen mining area. The development degree of coal resources in this area is relatively low. The area with a water level drop of less than $1 \mathrm{~m}$ is mainly located in the Salawusu formation in the west of the Yushen mining area. This area is not affected by coal mining; it is mainly affected by the seasons, precipitation, evaporation, and human activities of upstream. The drop of the water level is small in recent years. The overall decline of the water level in the study area decreased the outcropping quantity of spring (group).

4.3.2. Intensive Mining Is the Direct Cause of Regional Water Level Decline. The development of coal resources in the study area started in the late 1980s. The first modernized coal mine (Daliuta) was constructed and operated in 1996. After that, many coal mines were constructed. The raw coal output in the area was 36 million tons in 2000, and it reached 3.558 tons in 2015 , accounting for $9.62 \%$ of the raw coal production of nation's total. It forms the main coal base of China with Erdos City in the Mu Us Desert. Especially in the upper reaches of Kuye River, the coal mines are present one after another. The diversion fissure zone formed by mining is connected to the main phreatic aquifer, causing the unwatering of the regional aquifer, decreasing the water table, and drying up the spring.

Compared with the water level in the 1980s, the water level of 14 wells around Hezegou and Qingcaogou in the study area of Jinjie coal mine all decreased to different degrees, with a drop of $0.5-12.67 \mathrm{~m}$. The average buried depth of Jinjie mine field was $\sim 1 \mathrm{~m}$ before the mining. The 


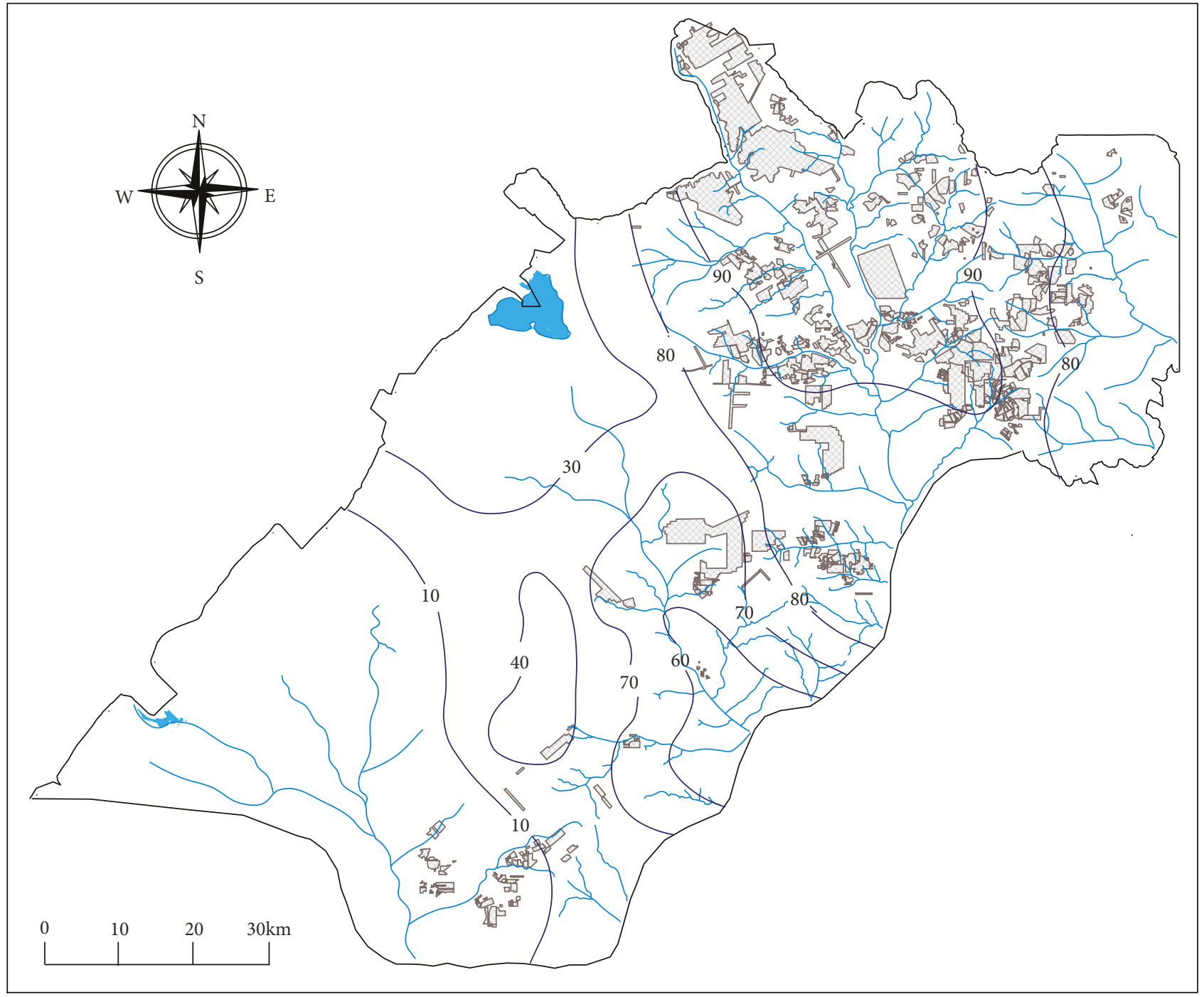

$\square 0-$ Attenuation ratio of quantity (\%)
Mined-out area

Figure 10: Contour map of the attenuation ratio of spring (group) flow.

intensive mining decreased the water level by an average of $6 \mathrm{~m}$. The decrease in the regional groundwater level decreased the discharge height of spring and quantity of spring. Thus, the higher the mining intensity, the more is the decrease of springs, as shown by the statistics of spring spots in mines with different mining intensities (Table 4).

\subsection{Ecological Efficiency Analysis of Mining}

4.4.1. Shrinking of the Wetland Area. From 1990 to 2011, the water area of the study area changed a lot, exhibiting a trend of continuous reduction. The water area of the entire region was $162.63 \mathrm{~km}^{2}$ in 1990 ; this decreased to $133.80 \mathrm{~km}^{2}$ in 2001 and continued to decrease to $85.69 \mathrm{~km}^{2}$ in 2011 , with a decrease of $\sim 40 \mathrm{~km}^{2}$ every 10 years. The reduction rates of the two decades were $17.73 \%$ and $35.96 \%$, respectively. The decrease in surface water was mainly manifested in the lakes and reservoirs and narrowing of some river basins. This was mainly manifested in the shrinking of water surface of lakes and reservoirs such as Hongiiannao, Zhongyingpan Reservoir, Xuji Haizi, and Gouyancun Haizi. The water area of Wulanmulun River, Beiniuchuan, and Yuxi River narrowed. For example, in the case of Hongjiannao (Figure 13), a desert freshwater lake formed in 1929. From the 1970s to the early 1990s, the lake was balanced and the water level was basically stable. From the late 1990 s to 2002, the water level of Hongjiannao decreased by $10-15 \mathrm{~cm}$ every year. After 2002, the water level decreased by $20-30 \mathrm{~cm}$ every year, with a maximum of $40 \mathrm{~cm}$. The Hongjiannao area also underwent shrinking, from a maximum of $70 \mathrm{~km}^{2}$ in 1969 to $32 \mathrm{~km}^{2}$ in 2014 . This 


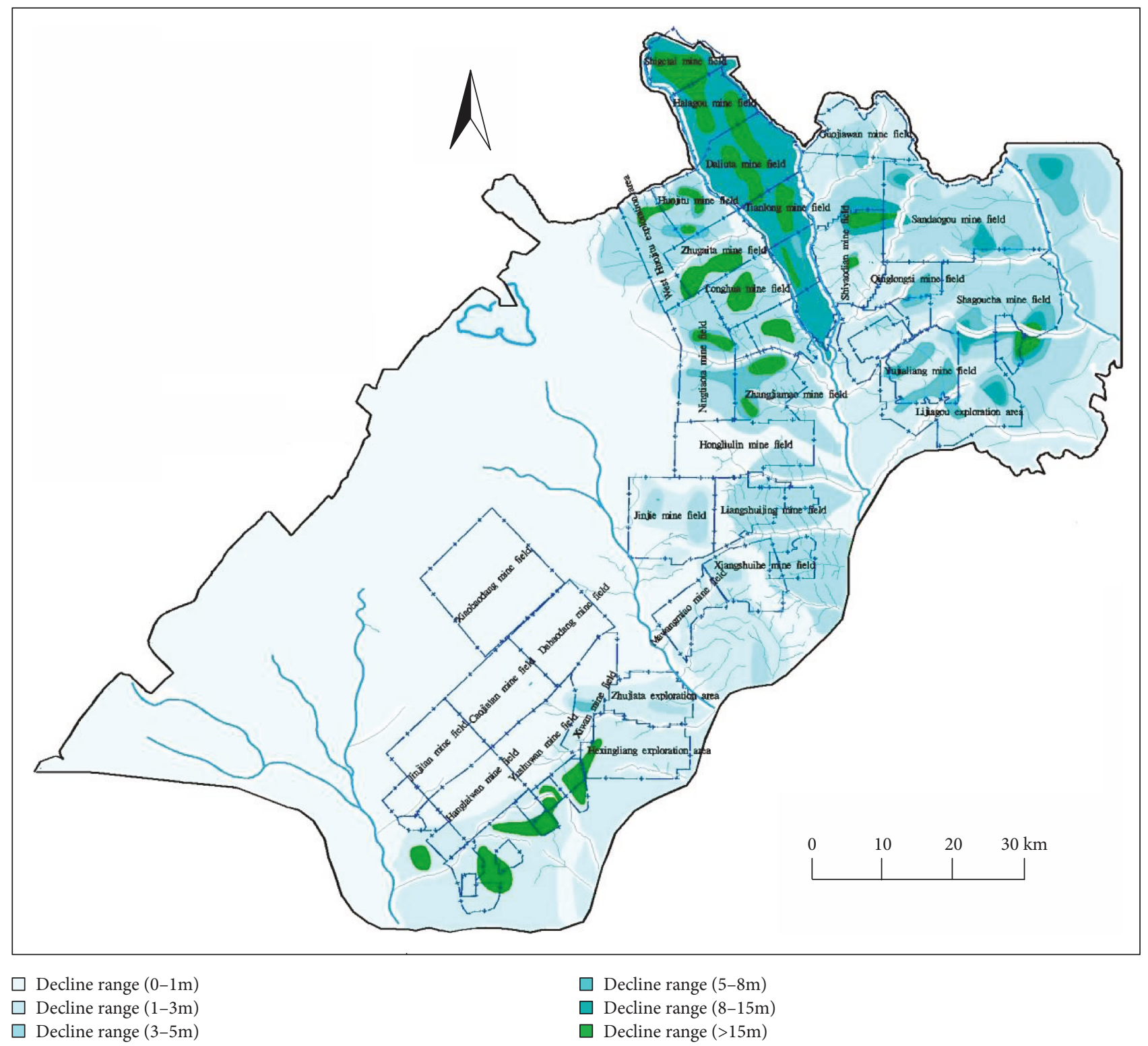

FIGURE 11: Partition of decline range of the groundwater table in recent 21 years.

is related to intensive human engineering activities including coal mining in Hongjiannao Basin.

4.4.2. Reducing Runoff of Surface Water. The Kuye River in the study area was cutoff since 2000, and the days of cutoff increased continuously from 2000 to 2002, reaching a maximum of 220 days. The days of cutoff from 2003 to 2005 exceeded 150 days, almost becoming a dry river. The river basin of Wulanmulun River and Beiniuchuan in the upper reaches of Kuye River was cutoff in most of the tributary trenches. For example, Shuanggou is a tributary of Wulanmulun River in the upper reaches of Kuye River with a length of $5.6 \mathrm{~km}$. The annual average of spring flow is $7344 \mathrm{~m}^{3} / \mathrm{d}$. The mouth of spring dried up in 1997, the brook was cutoff intermittently, and the watery land became a dry land.
4.4.3. Quality Reduction of Cultivated Land. The spring water in the eastern edge of desert dried up, cutting-off some rivers. The soil structure became loose, and the corrosion resistance of culvert water decreased, resulting in the desolation of valley land and decrease in the quality of cultivated land. The villagers used to depend on the selfsufficiency of crops planted on both sides of the riverbed. Because the quality of cultivated land decreased, the crops could not grow and the villagers had to change their means of living.

4.4.4. Vegetation Degradation. The natural attribute of the study area is dry steppe, an integral part of grassland resources in northern China. Suitable vegetation and shrubs are drought-sensitive and cold-resistant. They have the 

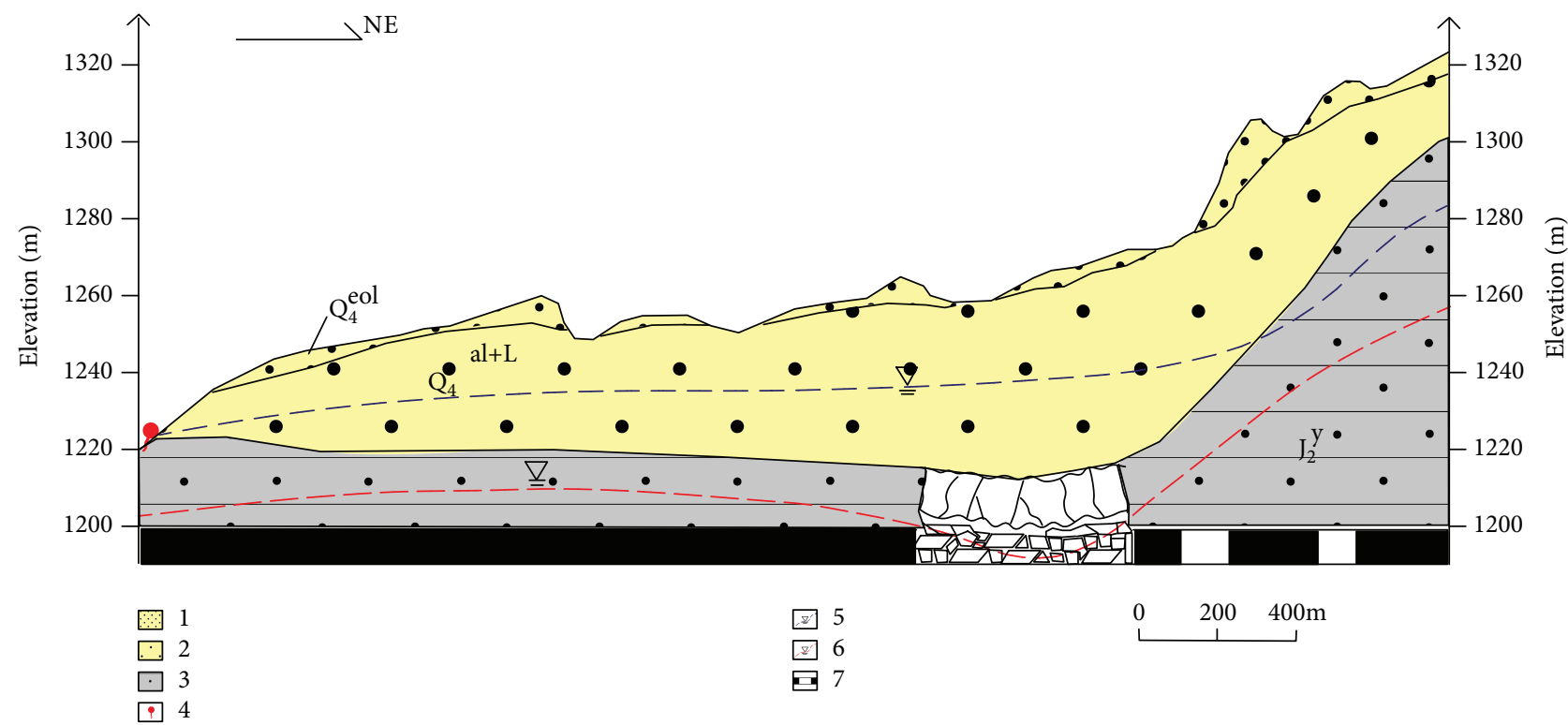

FIGURE 12: Schematic diagram of spring drying mechanism in Hala Ditch of Kuye Basin. 1: Silty fine sand; 2: intermediate fine sand; 3: sandstone; 4: drying spring; 5: groundwater level before mining; 6: groundwater level after mining; 7: mined-out area.

TABLE 4: Statistics of springs' evolution in different mine fields.

\begin{tabular}{|c|c|c|c|c|c|c|c|}
\hline Mine field & $\begin{array}{c}\text { Coal mining } \\
\text { intensity } \\
\text { level }\end{array}$ & $\begin{array}{l}\text { Quantity of } \\
\text { springs before } \\
\text { coal mining }\end{array}$ & $\begin{array}{c}\text { Quantity of } \\
\text { springs after coal } \\
\text { mining }\end{array}$ & $\begin{array}{l}\text { Attenuation } \\
\text { ratio of } \\
\text { quantity }(\%)\end{array}$ & $\begin{array}{l}\text { Spring flow } \\
\text { before coal } \\
\text { mining }(\mathrm{L} / \mathrm{s})\end{array}$ & $\begin{array}{l}\text { Spring flow } \\
\text { after coal } \\
\text { mining }(\mathrm{L} / \mathrm{s})\end{array}$ & $\begin{array}{c}\text { Attenuation } \\
\text { ratio of spring } \\
\text { flow }(\%)\end{array}$ \\
\hline $\begin{array}{l}\text { Yujialiang } \\
\text { mine field }\end{array}$ & Highest & 11 & 4 & 63.6 & 25.186 & 3.226 & 87.1 \\
\hline $\begin{array}{l}\text { Zhangjiamao } \\
\text { mine field }\end{array}$ & High & 145 & 39 & 73.1 & 77.46 & 26.3103 & 66 \\
\hline $\begin{array}{l}\text { Dabaodang } \\
\text { mine field }\end{array}$ & Low & 8 & 8 & 0 & 656.301 & 145.63 & 77.8 \\
\hline
\end{tabular}

characteristics of narrow foliage, well-developed root, low canopy density, and seasonal variation. In recent years, owing to the increase in good management such as returning farmland to forests and grass and planting grass and trees, the vegetation has a trend of good transformation. However, the improvement of vegetation ecology in mined-out areas is significantly smaller than that in adjacent areas, indicating that coal mining negatively affects vegetation ecology. Especially in small local coal mines, vegetation is further degenerated. Poor growth, withered and yellowing of leaves, and death or withering of some willows were observed (Figure 14).

\section{Conclusions}

(1) Spring spots can be divided into three types according to the supply source of dry season spring spot, namely, (i) recharge spring spot of sand infiltration, (ii) recharge spring spot of loess infiltration, and (iii) recharge spring spot of mixed infiltration. Before large-scale mining, the main characteristics of three types of spring spots are as follows: (i) the maximum amount of single water inflow of springs with sand infiltration recharge was more than $10 \mathrm{~L} / \mathrm{s}$, (ii) the total quantity of springs with mixed infiltration recharge was the most, and (iii) the ecological effect of springs with loess infiltration recharge was the most significant.

(2) 2580 springs (group) were distributed in the Yushenfu mine area before the large-scale mining with a total flow of $4998.9428 \mathrm{~L} / \mathrm{s}$ in 1994. 376 residual springs (group) were present after the large-scale mining with a total flow of $996.392 \mathrm{~L} / \mathrm{s}$ in 2015 . Thus, intensive mining decreased the regional groundwater level, decreasing the amount of spring water.

(3) After the decrease in the groundwater table caused by intensive mining, the area of water and wetland in the Yushenfu mine area also decreased. The water area in the region decreased from $162.63 \mathrm{~km}^{2}$ in 1990 to $85.36 \mathrm{~km}^{2}$ in 2011 . The wetland area decreased from $55.86 \mathrm{~km}^{2}$ in 1990 to $45.49 \mathrm{~km}^{2}$ in 2011 . Because of the decrease in the water table, the shrinking area of 


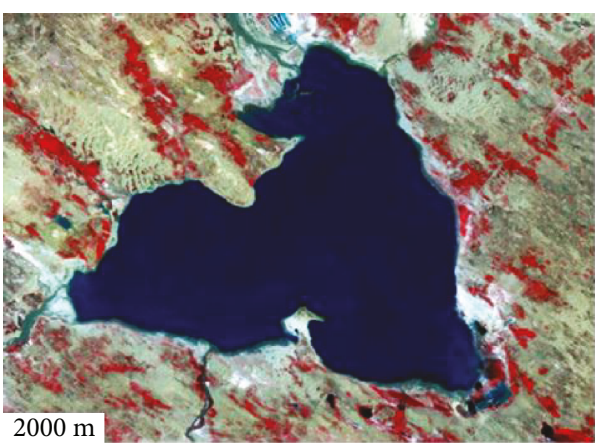

(a)

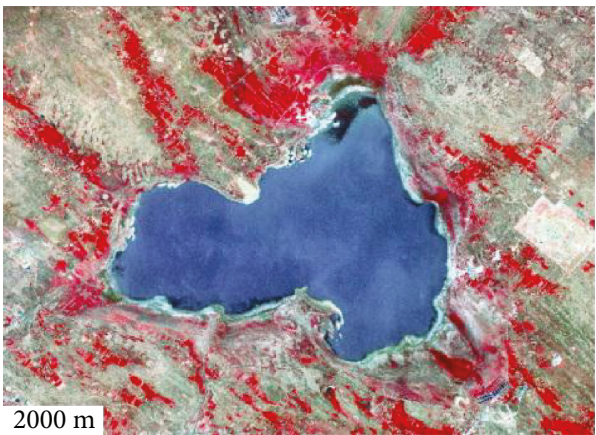

(c)

$$
\begin{array}{r}
1990 \\
-\quad 2001 \\
-\quad 2011
\end{array}
$$

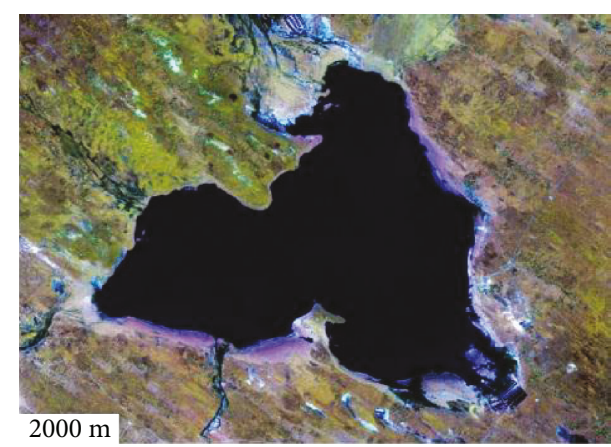

(b)

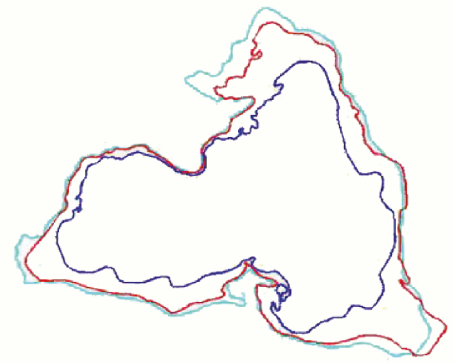

$2000 \mathrm{~m}$

(d)

FIGURE 13: Photographs of vegetation degradation. (a) Remote sensing image in 1990, (b) remote sensing image in 2001, (c) remote sensing image in 2011, (d) boundary of Hongjiannao in different stages.

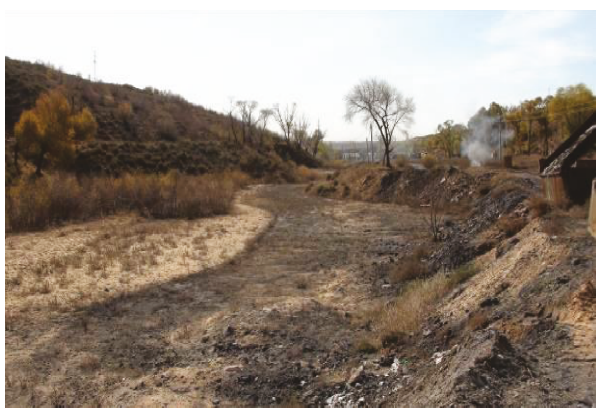

(a)

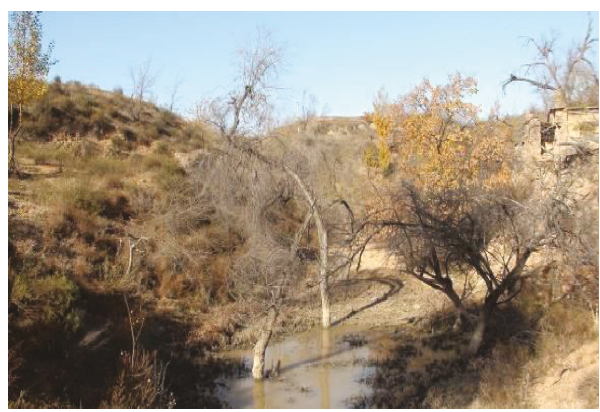

(b)

FIGURE 14: Photographs of vegetation degradation.

water and wetland, and reduction in spring groups, the quality of cultivated land decreased, vegetation degraded, and some willows became dead or slightly withered in the study area.

\section{Data Availability}

The data used to support the findings of this study are available from the corresponding author upon request.

\section{Conflicts of Interest}

No potential conflict of interest was reported by the authors.

\section{Acknowledgments}

The authors thank the geological survey members for their valuable suggestions on this study. Special thanks are due to the encouragement of academician, Minggao Qian, from China University of Mining and Technology; thanks are 
due to the guidance of academician Shuangming Wang of Shaanxi Geological Survey Institute. Thanks are also due to the colleagues for field investigation: Jianmin Ning, Yiping He, Hainan Liu, Jiangli Du, Chaowei Yao, Huiying Bian, Wenli Li, Hui Jiang, Shuai Cheng, Ruijun Ji, etc. The authors thank the colleagues of the author, Limin Fan, from the 185 Coalfield Geology Co. Ltd. of Shaanxi Province; their fruitful work led the foundation for the completion of this article. The authors also thank Xiaotuan Zhang, the director of project management department, Tao Shen, the vice-director of project management department, and Hongqiang Zhang, the senior engineer from Shaanxi Geological Survey Institute for the project's support. Without their support and participation, this article would be almost impossible to complete. The research was supported by the Major State Basic Research Development Program of China (973 program), Project no. 2013CB227901, Science and Technology Promotion Program of Shaanxi Province, Project no. 2011TG-01, Public Welfare Geological Survey Project of Shaanxi Province, Project no. 2013020101, and open fund of Key Laboratory of Mine Geological Hazards Mechanism and Control, Project no. KF2017-12.

\section{References}

[1] L. M. Fan, X. D. Ma, and R. J. Ji, "The progress of research and engineering practice of water-preserved coal mining in western eco-environment frangible area," Journal of China Coal Society, vol. 40, no. 8, pp. 1711-1717, 2015.

[2] C. Toumey, "Science policy in the days of Trump," Nature Nanotechnology, vol. 12, no. 10, pp. 934-935, 2017.

[3] S. Spiegel and B. Brown, "Fossil fuels: heed local impact of coal mining," Nature, vol. 550, no. 7674, p. 43, 2017.

[4] N. Gilbert, "Mountain mining damages streams," Nature, vol. 466, no. 7308, p. 806, 2010.

[5] L. M. Fan, "Environmental geology in Shenmu mining area," Hydrogeology \& Engineering Geology, vol. 19, no. 6, pp. 3740, 1992.

[6] X. M. Wu and L. G. Yang, "Distribution characteristics and formation conditions of springs in south Mu Us Desert, North Shaanxi Province," Hydrogeology \& Engineering Geology, vol. 25, no. 1, pp. 23-26, 1998.

[7] L. M. Fan, "Discussing on coal mining under water-containing condition," Coal Geology ఓExploration, vol. 33, no. 5, pp. 5053,2005

[8] L. M. Fan, "On the water-preserved mining," Journal of China Coal Society, vol. 42, no. 1, pp. 27-35, 2017.

[9] S. M. Wang, Q. X. Huang, L. M. Fan, Z. Y. Yang, and T. Shen, "Study on overburden aquifer and water protection mining regionalization in the ecological fragile mining area," Journal of China Coal Society, vol. 35, no. 1, pp. 7-14, 2010.

[10] Z. M. Xu, S. Gao, S. M. Cui, Y. J. Sun, Z. S. Chen, and J. F. Wu, "Hydro-geological basic and practice for water-preserved mining in ecologically vulnerable area: a case study in Hami coalfield," Journal of China Coal Society, vol. 42, no. 1, pp. 80-87, 2017.

[11] Q. X. Huang, "Simulation of clay aquifer stability of water conservation mining in shallow-buried coal seam," Chinese Journal of Rock Mechanics and Engineering, vol. 28, no. 5, pp. 987-992, 2009.
[12] T. Li, Study on Aquifer-Aquifuge Structure Variation and Water Resources Dynamic Evolution with Large Scale Mining in Northern Shaanxi Province, China University of Mining and Technology, Xuzhou, Jiangsu, China, 2012.

[13] W. P. Li, G. J. Ye, Z. Lai, Z. H. Duan, and L. J. Cui, "Study on the engineering geological condition of protected water resources during coal mining action in $\mathrm{Yu}$-Shen-Fu Mine Area in the North Shaanxi Province," Journal of China Coal Society, vol. 25, no. 5, pp. 449-454, 2000.

[14] F. W. Zhang, Aquifer Reconstruction in Shallow Coal Seam Roof and Protection of Groundwater Resources under Mining Condition in Arid Areas, Geological Publishing House, Beijing, China, 2006.

[15] Y. D. Liu, The Technology and Usable Conditions' Classification of Aquifer-Protective Mining in Shallow Sand-BedrockCoal Seam, China University of Mining and Technology, Xuzhou, Jiangsu, China, 2008.

[16] Q. Wu, D. L. Dong, Z. H. Shi et al., "Row-for-ecological and environmental protection three-in-one combination of the North China type coal field," Science in China, vol. 29, no. 6, pp. 567-573, 1999.

[17] L. Ma, Z. Jin, J. Liang, H. Sun, D. Zhang, and P. Li, “Simulation of water resource loss in short-distance coal seams disturbed by repeated mining," Environmental Earth Sciences, vol. 74, no. 7, pp. 5653-5662, 2015.

[18] L. M. Fan, M. X. Xiang, and J. Peng, "Evolution analysis on springs in contiguous area of Maowusu Desert and Loess Plateau," Journal of China Coal Society, vol. 43, no. 1, pp. $207-$ 218, 2018.

[19] F. Wang, S. Tu, C. Zhang, Y. Zhang, and Q. Bai, "Evolution mechanism of water-flowing zones and control technology for longwall mining in shallow coal seams beneath gully topography," Environmental Earth Sciences, vol. 75, no. 19, article 1309, 2016.

[20] C. M. Côte, C. J. Moran, C. J. Hedemann, and C. Koch, "Systems modelling for effective mine water management," Environmental Modelling \& Software, vol. 25, no. 12, pp. 1664-1671, 2010. 

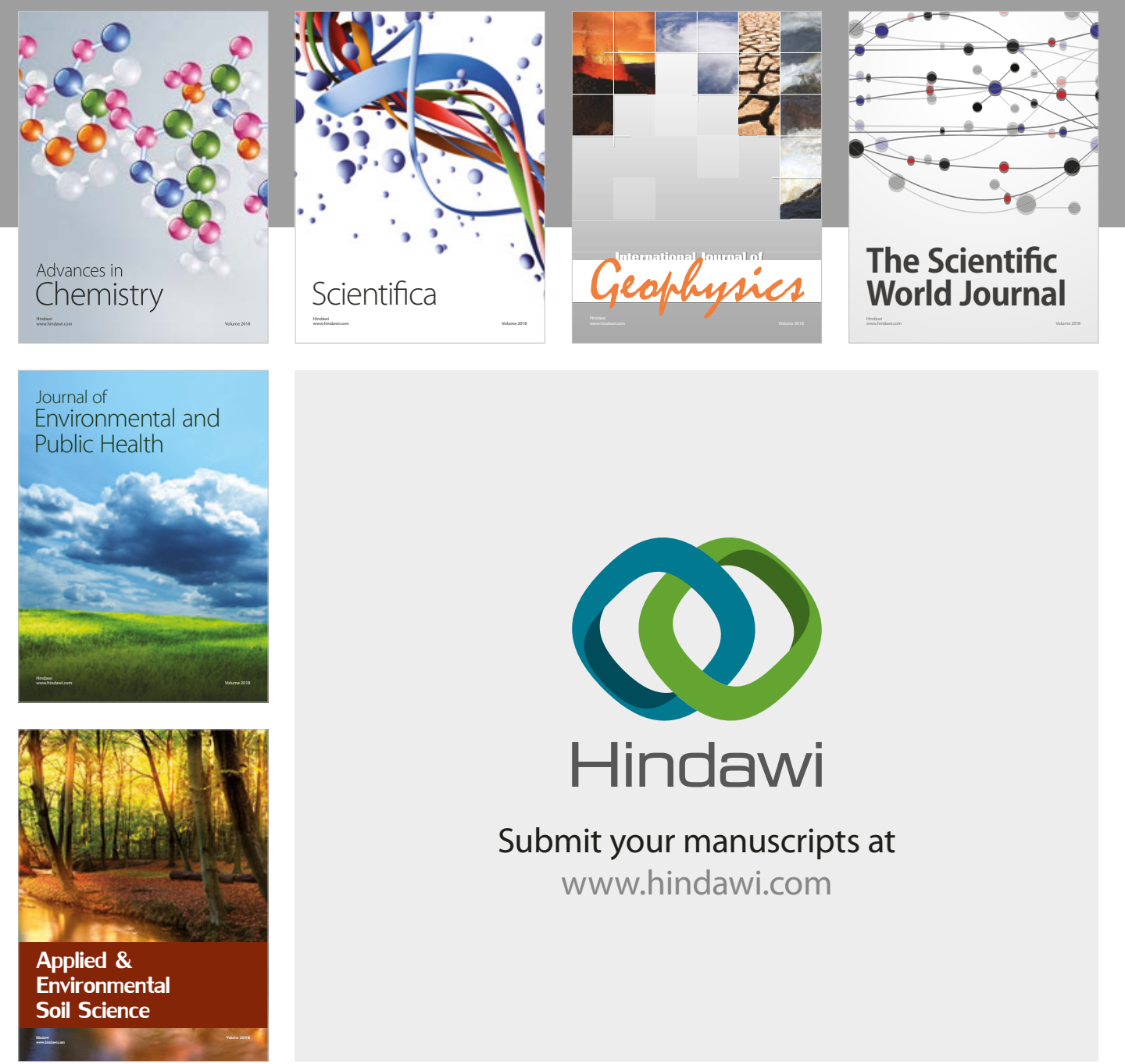

The Scientific

\section{World Journal}
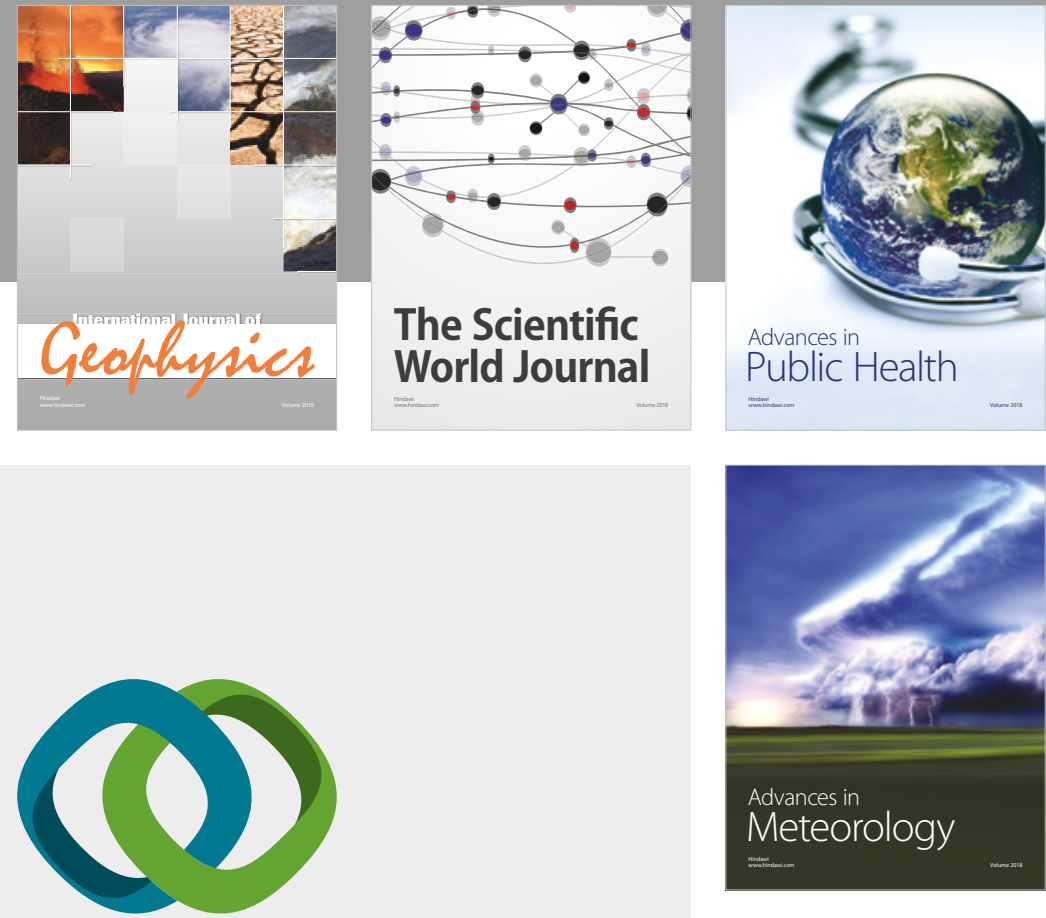

Advan

Public Health

\section{Hindawi}

Submit your manuscripts at

www.hindawi.com
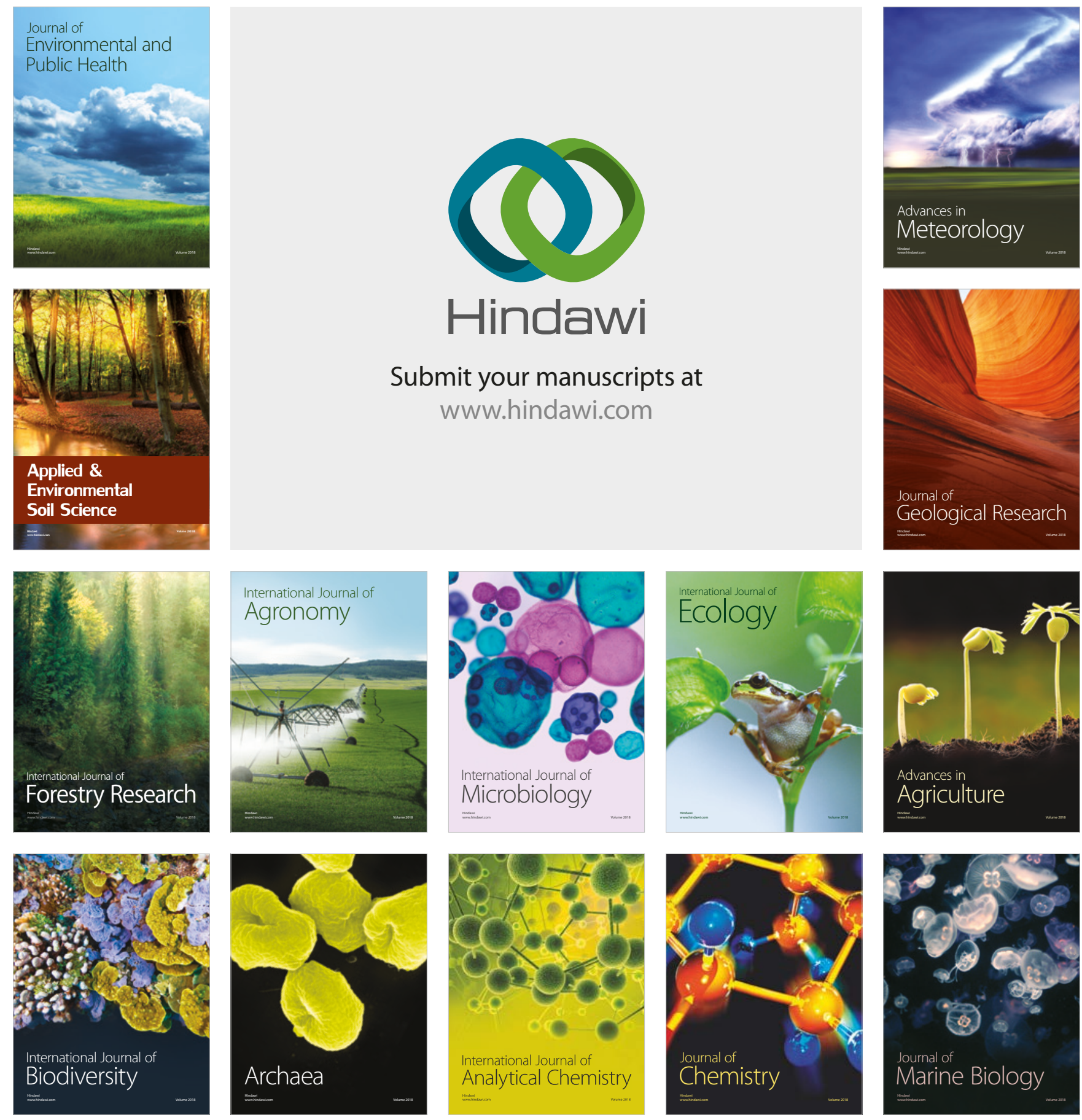